\title{
COMMENTARY
}

\section{All bleeding stops: how we can help...}

\author{
William P Riordan Jr** and Bryan A Cotton ${ }^{2}$ \\ See related research by Rossaint et al., http://ccforum.com/content/14/2/R52
}

\begin{abstract}
Rossaint and colleagues provide the critical care community with a comprehensive review of evidence-based data in an updated European guideline on management of bleeding following major trauma. In addition to reevaluating and grading recommendations carried forward from their previous work, they present new recommendations in areas such as coagulation support and monitoring, tourniquet usage, calcium, and desmopressin. Many of the recommendations are appropriately broad enough to promote the use of clinical judgment in the application of the guidelines.
\end{abstract}

In an updated European guideline on management of bleeding following major trauma, Rossaint and colleagues [1] make evidence-based recommendations relevant to the care of these patients. This work represents an update to guidelines previously published by the group in 2007 [2]

The challenge of providing comprehensive 'evidencebased' guidelines for the management of bleeding in trauma patients is readily apparent. The nature of the disease yields a broad range of patients - from the young and healthy to the elderly with multiple comorbidities. Moreover, the incredible variety of injury mechanisms in this diverse population guarantees that some studies will never be done. This is not discouraging, but rather an affirmation of the role of clinical judgment that is based on knowledge of published data, personal clinical experience, and the needs of each individual patient. As noted by Sackett and colleagues in their prescient commentary on evidence-based medicine [3]:

'Good doctors use both individual clinical expertise and the best available external evidence, and neither alone is enough. Without clinical expertise, practice risks

*Correspondence: william.riordan@vanderbilt.edu

'Vanderbilt University Medical Center, $121121^{\text {st }}$ Avenue South, 404 Medical Arts

Building, Nashville, TN 37212, USA

Full list of author information is available at the end of the article becoming tyrannised by evidence, for even excellent external evidence may be inapplicable to or inappropriate for an individual patient. Without current best evidence, practice risks becoming rapidly out of date, to the detriment of patients.'

An excellent example of the 'study that will never be done' is provided in the first recommendation: 'We recommend that the time elapsed between injury and operation be minimised for patients in need of urgent surgical bleeding control.' The implications of this are more complex when considered from the perspective of the individual patient, but can apply to anything that delays transfer to the operating room for control of bleeding. Unnecessary, and potentially dangerous, delays range from placement of the obligatory second "largebore IV' to imaging studies that may not change clinical management.

The authors recommend tourniquet use to stop lifethreatening bleeding from open extremity injuries in the pre-surgical setting (Grade 1C). Since they were conceived, tourniquets have been loved, hated, but never ignored. One of the earliest critics was none other than Claudius Galen (c. 129 to 200) who argued that squeezing a limb would simply force more blood from the wound [4]. This suggests that tourniquets of the time period did not routinely achieve sufficient limb-occlusion pressure. Given the early experience with newer devices from the conflicts in Iraq and Afghanistan, it is clear that a live patient with a tourniquet is preferable to a dead patient without one.

Coagulation monitoring is a formidable challenge in the bleeding trauma patient. In Recommendation 12, the authors note that International Normalized Ratio (INR) and Activated Partial Thromboplastin Time (APTT) alone should not be used to guide therapy. Such tests suffer from many limitations, including a one-dimensional and restricted view of an incredibly complex clotting system. In addition to emphasizing the role of platelets and fibrinogen, thromboelastometry is suggested with a Grade $2 \mathrm{C}$ recommendation. How thromboelastometry should be integrated into local protocols remains to be determined, and the authors acknowledge that more work remains to be done in this area. What currently limits the utility of conventional coagulation 
tests, and thromboelastometry as well, is the inherent delay in obtaining these values. When these test results return, they no longer reflect the coagulation state of the exsanguinating patient but rather show 'where they were' 30 to 45 minutes earlier. What is obvious is that a rapid and global assessment of the clotting cascade is still needed.

The authors recommend a target systolic blood pressure of 80 to $100 \mathrm{mmHg}$ until major bleeding has been stopped in the initial phase following trauma without brain injury. These recommendations are in agreement with the recent Eastern Association for the Surgery of Trauma and Tactical Combat Casualty Care guidelines $[5,6]$. Notably absent from the groups' recommendations are the exact ratios of blood components to be transfused. This is a responsible position given the ongoing global debate and paucity of quality data supporting a specific ratio. The lack of recommendations further support the need for a well designed, adequately powered, randomized trial to answer this question.

As trauma surgeons, it is interesting to speculate about future innovations. There may be a time when technology permits us to obtain a blood sample, and rapidly create a perfect whole-blood substitute enhanced for the physiologic status of the trauma patient. Or to administer an agent that targets wounded areas to achieve hemostasis without complications of thrombosis. Until then, the best we can do is to review the knowledge captured in excellent guidelines such as this one and use our best clinical judgment.
Competing interests

The authors declare that they have no competing interests.

\section{Author details}

'Vanderbilt University Medical Center, $121121^{\text {st }}$ Avenue South, 404 Medical Arts Building, Nashville, TN 37212, USA. ${ }^{2}$ Center for Translational Injury Research, 6410 Fannin Street, UPB 1100.20, Houston, TX 77030, USA.

Published: 6 May 2010

\section{References}

1. Rossaint R, Bouillon B, Cerny V, Coats TJ, Duranteau J, Fernández-Mondéjar E, Stahel PF, Hunt BJ, Komadina R, Nardi G, Neugebauer E, Ozier Y, Riddez L, Schultz A, Vincent JL, Spahn DR, Task Force for Advanced Bleeding Care in Trauma: Management of bleeding following major trauma: an updated European guideline. Crit Care 2010, 14:R52.

2. Spahn DR, Cerny V, Coats TJ, Duranteau J, Fernández-Mondéjar E, Gordini G, Stahel PF, Hunt BJ, Komadina R, Neugebauer E, Ozier Y, Riddez L, Schultz A Vincent $J$, Rossaint $R$, Task Force for Advanced Bleeding Care in Trauma: Management of bleeding following major trauma: a European guideline. Crit Care 2007, 11:R17.

3. Sackett DL, Rosenberg WM, Gray JA, Haynes RB, Richardson WS: Evidence based medicine: what it is and what it isn't. BMJ 1996, 312:71-72.

4. Forrest RD: Early history of wound treatment. J R SoC Med 1982, 75:198-205.

5. Cotton BA, Jerome R, Collier BR, Khetarpal S, Holevar M, Tucker B, Kurek S, Mowery NT, Shah K, Bromberg W, Gunter OL, Riordan WP Jr; Eastern Association for the Surgery of Trauma Practice Parameter Workgroup for Prehospital Fluid Resuscitation: Practice management guidelines for pre-hospital fluid resuscitation of the injured patient. J Trauma 2009, 67:389-402.

6. Tactical Combat Casualty Care Guidelines [http://www.health.mil/Libraries/ Presentations_Course_Materials/TCCC_guidelines_090204.pdf]

doi:10.1186/cc8969

Cite this article as: Riordan WP, Cotton BA: All bleeding stops: how we can help... Critical Care 2010, 14:146. 